Article

\title{
Learning Spatial Design through Interdisciplinary Collaboration
}

\author{
Martin Bryant
}

check for updates

Citation: Bryant, M. Learning Spatial Design through Interdisciplinary Collaboration. Land 2021, 10, 689. https://doi.org/10.3390/land10070689

Academic Editor: Bruno Marques

Received: 16 April 2021

Accepted: 21 June 2021

Published: 30 June 2021

Publisher's Note: MDPI stays neutral with regard to jurisdictional claims in published maps and institutional affiliations.

Copyright: (C) 2021 by the author. Licensee MDPI, Basel, Switzerland. This article is an open access article distributed under the terms and conditions of the Creative Commons Attribution (CC BY) license (https:/ / creativecommons.org/licenses/by/ $4.0 /)$.
School of Architecture, Faculty of Design Architecture Building, University of Technology Sydney, Ultimo, NSW 2007, Australia; martin.bryant@uts.edu.au

\begin{abstract}
Spatial design at interior, site, city and regional scales is increasingly complex, and will continue to be so with the uncertainty of the climate crisis and the growing place-based intricacies of pluralist societies. In response to this complexity, professional design practice has pursued new ways of working. More design projects are becoming more interdisciplinary and less hierarchically structured, involving more collaborative project teams with a variety of backgrounds in architecture, urban design, landscape and interior architecture, engineering, ecological sciences and art. At universities, the design-learning studio which pedagogically champions the authentic replication of design practice projects, has also bifurcated. While teaching design through the traditional disciplinarybased problem-solving processes of an individual project is still understandably commonplace, a new type of studio has emerged, led by group work and interdisciplinary collaborations, and framed by the complexity of a seemingly irreconcilable problematic subject. This emergent domain warrants more research into pedagogical structures, teaching techniques and learning activities; and this paper explains such investigations undertaken through the live educational practice of two interdisciplinary studios in two years, drawing conclusions from student feedback gathered via questionnaires and focus group interviews. The findings suggest that teaching formats in this type of studio need to facilitate a balance between trusting relationships and immersive experiences; and that effective teaching techniques entail the development of more accessible communication techniques in conceptual diagramming and linguistic idiom.
\end{abstract}

Keywords: landscape architecture; design language; critique; divergence

\section{Introduction}

\subsection{The Court's Critic}

There is a fool in Shakespeare's As You Like It called Touchstone whose role, as his name suggests, is to expose hidden values. He is both an active player in the court, and a commentator on its behaviour, questioning the characters' arguments, confronting them with alternative truths, and challenging them with transformative practices [1]. Rosalind, the story's heroine, sees the duelling source of his dual talents: 'Fortune makes Nature's natural the cutter-off of Nature's wit.' [2] She is suggesting that 'Nature' imbues Touchstone with the wherewithal of wit and critique, but 'Fortune' makes him effective in deploying these skills.

The antipathy between Nature and Fortune may persist in spatial design's dilemmas that Stan Allen dissected when he proposed three important tasks for spatial design schools today [3]. One of these tasks is transformative: the diminishing traditional domain of spatial designers warrants educators to find the potential of alternative disciplinary practices. The second is divergent: because our plural societies embed intricately layered viewpoints, the student needs to learn to navigate between traditional pedagogical competency landmarks with the unknown waters of fearless independence. The third is critical: accompanying the proliferation of information and access, learning requires a very mature capacity for judgement and discernment in a world of unlimited choices. These transformative, divergent and critical skillsets may be essential in today's complexity, but they are not altogether new to spatial design teaching. In 1991, John Chris Jones described the need for 
students to look outside what comes naturally, to experiment with divergent practices and explore beyond the span of disciplinary norms [4]. And Jackie Bowring in 2000 reinforced the significance of critical thinking skills [5]. As Kathryn Moore explains, these processes help the student to question seemingly unequivocal disciplinary logic, draw out inherent ambiguities in normative practices, and speculate on sets of alternative criteria to frame design [6].

Can the disciplinary tutor teach these skills? Or, do we need another enabler? Shakespeare's Touchstone may be a role model: an outside force with inside knowledge. In spatial design this might be someone who knows the orthodoxies of place-based design, but can challenge thinking and methods from outside a disciplinary comfort zone. At spatial design school studios today, the most effective and readily available touchstone may occur in the partnership of interdisciplinary student peers-architects, interior architects and landscape architects-who know the spatial design 'court' but are sufficiently detached from the normative disciplinary-based decision-making process peculiar to each other's spatial design discipline.

The notion that any student, from any discipline, can learn from other disciplines to address complex matters is well established. Some schools, which see beyond the superficiality of generic 'design thinking' as a way of bridging disciplinary gaps, have established transdisciplinary classrooms, where they focus on the problems-or the problematicrather than the solution, and where they encourage criteria-based formulations of frame making as mechanisms to shift disciplinary boundaries and thereby imbue expansive thinking [7]. In almost any field, these processes, which build on disciplinary expertise, promise innovative opportunities for real-world problematics [8]. So how are they specifically useful for spatial designers?

There is arguably a framework that makes spatial design disciplines distinctive. It is built around the intelligibility of space [9] and its potential to influence social behaviour; the slow time needed to know/feel/sense it [6,10] through motion, form and identity [11]; the science of its materiality; its varied scales and contexts, its distance and closeness, foreignness and security, and its contested 'boundaries between private and public, between internal and external, between real and virtual' [11]. Because its medium is seldom deterministic [3] and often ambiguous [11], it is open to interpretation. And its design is open to interdisciplinarity. In all this vastness, spatial design is an expandable field of knowledge. Rosalind Krauss saw the potential in 1979 to expand the discourse of sculpture into landscape and architecture [12]; Jane Rendell's 2003 critical spatial practice recognised that the sometimes messy interdisciplinary engagements between architecture, art and the public heightened divergent possibilities [13]; and Mark Burry in 2012 encouraged practice between disciplines because it actually sharpened disciplinary expertise via shared space [14]. And yet, despite this interdisciplinary trajectory, there are hurdles to learning through interdisciplinarity, such as the funding of tutors from different disciplines [14]. One way to overcome this might be to research which teaching formats and techniques might make interdisciplinary studios efficient as well as effective.

This research explored the ways that interdisciplinary collaboration in the spatial design studio helped students learn to become better critics and to work more divergently. It entailed an action research methodology that used live studios and student feedback to reflect on the beneficial teaching and learning strategies that reinterpret traditional disciplinary roles and power relationships. The outputs were briefly reported on in a short essay entitled 'Touchstones in Design' [15]. In this paper, I now contextualise the findings and expand the discussion to address the ever-increasing need for creative and innovative design approaches [16] that will generate sustainable shifts across planetary systems [17].

\subsection{Interdisciplinary Collaboration in Spatial Design Practice}

The spatial design disciplines in professional design practice-including architecture, urban design, landscape and interior architecture, engineering, ecological sciences and art-have now become more actively collaborative and interdisciplinary as they tackle 
the open-endedness of landscape, urban and territorial scaled projects which are seldom approachable within the bandwidth of any traditional mono-disciplinary skillset [18]. Healey [19] suggests these collaborations show that traditional challenges like spatial coherence and hierarchy are disappearing. In their place, wicked problems are surfacing, such as the crisis of climate change which has led to the emergence of novel ecosystems and biodiversity loss, which is accelerated by ecological fragmentation and monocultures of grey urban infrastructures and suburban sprawl [16], brought on by the social issues of mass migrations, and their diversely layered culturally specific knowledge systems. The complexity may not be causal, but it correlates across multi-dimensions [20]. To respond, landscape, urban design and architectural processes have had to become more inclusive and more consensual with more discourse [21]. In place of hierarchies, flatness has generated participatory design, where lay communities use their democratic mandate to contribute to design outcomes. For spatial design disciplines' practices, the flattening has influenced the modes of working with each other. The traditional multidisciplinary project with discipline-specific briefs and coordinated but compromised solutions [14], which Wood [22] argues dilute the strength of each discipline, may still be dominant. But it is giving ground to interdisciplinarity practices which champion the conceptual integration of diverse values and knowledge capacity, which devolves disciplinary hierarchies without losing disciplinary distinctions, and which encourages argumentation and confrontation that can inherently address complex problems [23].

In the literature surveyed for this research there appears to be evidence of three productive and interrelated techniques that make interdisciplinary design work: one is trust, another comes from clear communication, and the third is the immersion of spatial designers into an abstracted conceptual space.

In 2015, Google's Project Aristotle emerged with two findings into their five-year study on what makes a team work: equal airtime and body language literacy. In the world of data analytics, the trust embedded in these paradoxically old-fashioned qualities of listening and empathizing may seem somewhat underwhelming [24]. In the technology infused world of spatial design, where hierarchically structured projects were once commonplace, trust is an important cornerstone for co-led, co-designed projects that share ownership of outcomes. The implication of 'co-' prefixes is that language plays an important part in this sense of trust between collaborators. And yet language, for spatial designers has sometimes driven obfuscation: Robin Evans described architects who fabricate 'virtual meanings for the drawing to represent in place what they know they cannot find' [25]. And Moore calls the linearity of language an interpretive veil, a barrier to seeing the world [6]. Language is, therefore, both a problem and an opportunity that needs to be addressed when we collaborate, especially when participants are mandated equal airtime.

Another way of generating trust, according to Botterill [26] after observing interdisciplinary collaboration processes between web designers and graphic designers, is the start-up process which looks for consensus on goals, and boundaries. If disciplinary boundaries are, on one hand, too porous or, on the other, too impervious, there is contested space, leading to a lack of respectful horizontal discourse and an unwillingness to compromise. What this means is that there needs to be a diagrammatic language for interdisciplinary exchange that can foster the empathetic verbal language which Google found essential for collaboration.

While a new language and start-up techniques can frame successful collaborations, conceptual modelling liberates a project by encouraging immersion in a shared abstract perception of space [6]. Immersion in a conceptual model offers potential to 'migrate between disciplines,' offering new ways of creative thinking [27] for knowledge production [18]. This is because, Wheatley [28] argues, 'Innovation is fostered by information gathered from new connections, from insights gained by journeys into other disciplines or places, and from active, collegial networks and fluid, open boundaries. Innovation arises from ongoing circles of exchange, where information is not just accumulated or stored, but created. Knowledge is generated anew from connections that weren't there before.' The migration of conceptual models between science, philosophy and the arts has 
always been appealing, but spatial design disciplines have traditionally been passive in this exchange-accepting ideas from, for example, cinema or literature, but rarely reversing the flow [26]. Interdisciplinary collaborations can encourage the journey into a shared space to arrive at conceptual modelling that is both rich and productive.

\subsection{Interdisciplinary Collaboration in Education}

Spatial designers have been and still are trained to use a problem-solving process within which individuals conceptualise, schematize and craft [29] creative products [30]. Tasks usually include testing and improvising repeatedly in any sequence at a variety of physical scales [31]. At university, the need for individual assessment invites competition rather than collaboration. This process and its product have been set up partly by society's values, and partly by the profession's [32]. It is an experiential model of education where students learn by doing. And yet, 'no new thing, no originality or creativeness, is going to emerge if one sticks rigidly to an orderly design process in which one never gets in a mess, never loses touch with one's preconceptions, never lets go of the KNOWN' [4]. Herein is one of the paradoxes of design education: that the creativity of divergent thinking has sat outside the paradigm of supposedly creative design learning. Downton [31] sees this as a product of the dominant framework of educational approaches that are 'culture-preserving processes infrequently intended to encourage divergence'. Furthermore, design critique, rather than being integrated in the learning process, is seen as a skill that comes when designers, post-graduation, can thread theory into practice [5]. At university, critique has primarily been used as a confirmation that the final design does as intended. Press [30] concludes that the educational design studio has been a way to learn how to solve problems rather than critically question them.

The interdisciplinary collaboration studio is a methodological model which maintains a requirement for discipline specific content while encouraging skill development through extraneous experiences [33] that scratch beneath disciplinary veneers. In this new paradigm of design education, creativity and critique have a symbiotic relationship because, as Csikszentmihalyi (in Cowdrey et al.) suggests, this model 'accepts teaching of creativity in terms of critical analysis' [33]. So how might we expedite this process and create a generation of critical designers who are interested in going into the unknown, and have the critical skills to deal with it? It is perhaps surprising, given professional practice's acceptance of interdisciplinary collaboration, that educational studios have limited discourse on teaching formats and techniques, especially as there is a proliferation of multidisciplinary spatial design schools which could provide the locus for these discussions. Wood [23] suggests that this may be because most faculties do not know how to teach it, and many students are afraid rather than challenged by the prospect of possibly agonistic partners.

Nonetheless, collaborative learning and teamwork are well documented as necessary to modern higher education courses [34,35]. Cooperative learning is growing in universities and is considered to be equally or more effective than lecturing in a wide range of courses [34]. A literature review of collaborative learning identifies a number of benefits that arise from student collaborations in tasks, such as more debate, more risk taking, sharing experiences, more transparency taking participant and observer roles (similar to action and reflection, or critique), creating a variety of perspectives, developing individual strengths, recognising authenticity, resolving and embracing ambiguities, motivation, and organization [27,35-37]. Sanoff [38] says there is a growing body of evidence now which recognises that education in the spatial design disciplines needs to embody participation in and responsibility for collective decision making. Baumber [39] goes even further and argues for the benefits of student-staff transdisciplinary partnerships - a far cry from the master-apprentice model—because they could draw on 'multiple knowledge types through a reflexive process'.

Wood's tests [23] on interdisciplinary collaboration in design concluded that the pedagogical benefits were in reflexivity, which pedagogically mature students could undertake with confidence as they had a grasp of the disciplinary norms and were able to 
challenge them. However, having a grasp of norms does not necessarily generate creative outcomes. It would seem that research could extend this conclusion and explore how reflective observation catalyses the design process.

Kendall [40] documented a studio scenario, where students in interdisciplinary teams were asked to interact to develop design skills specific to their own discipline. Students shared the construction of a concept which became 'the constraint'. He then 'distributed' the design so that students worked individually on parts governed by the 'constraint'. The results showed that the quality of student work was not jeopardised by the constraint, that poorer students tended to benefit most, and that working partly individually and partly collaboratively was motivating. Kendall's research shows some interesting teaching and facilitation techniques but does not draw a useful correlation between these techniques and design process learning.

These studies serve as a benchmark for researching the teaching of interdisciplinary design, showing the benefits of working with pedagogically mature students, and mixing up individual work with group work. However, they do not seem to have explained what format of interdisciplinarity helped students learn to design, or what techniques worked. This is a key area which this research methodology was set up to explore.

\subsection{Research Questions}

The benefits of interdisciplinary collaboration in the professional practice workplace are becoming well-documented, so it seems imperative that we align architectural design education with workplace practice and develop knowledge of interdisciplinary collaboration for the benefit of learning design. This research sets out to address these aims by asking the following question:

What teaching techniques and formats enable design learning for complex problems in collaborative interdisciplinary studios?

\section{Methods}

To address this question, I used a form of action research where teachers structured the live educational practices of design studios so as to integrate the research into interdisciplinary collaboration within the studio learning environment. During and after each meeting, a reflection of the learning experience and outcomes was expressed in journals, informed by students' views and teachers' perceptions. Educational practices were adapted in response to the feedback loop. The reflective process was then recycled and re-applied iteratively. This process recognises that design, teaching design and acquiring skills are all subjective in nature, and that the learning process of an interdisciplinary collaboration entails incremental personal transformations of design practice rather than significant or decisive shifts in student learning. Deming and Swaffield [41] note that improved educational practices generally emerge when students have empowerment in the process, and when students have dialogue with researchers as part of the reflective process. On this basis, the research will draw conclusions from a methodology that relies predominantly on student self-reporting.

We convened a studio of twenty fourth-year landscape architecture with twenty-five fourth-year interior architecture students; the following year, a studio of twenty third-year architecture students collaborated with twenty third-year landscape architecture students. Both studios worked on a teacher-chosen site, though architects worked on buildings, landscape architects on the broader context, and interior architects on the interior of an existing building. Both studios' duration was twelve weeks (one trimester), which provided ample time to trial collaborative and individual work. Teacher/student meetings were conducted for three hours, twice a week. Two disciplines were enrolled in each studio: interdisciplinary collaboration was trialled on a two-person partnership; thus, avoiding the logistical problems of large groups and the complexity of multiple interdisciplinary collaborations. Using different students in each year facilitated the potential to adapt research findings from one year to improve educational practices and retest the next. We 
chose fourth-year and third-year students in recognition of the need for students to be sufficiently advanced in their core skills before they encountered other disciplines, and even then we delayed third year collaborations until a point in the trimester when we were confident that their core skills gave them confidence to embark on an interdisciplinary project.

Students worked partly by themselves and partly in a collaboration with students from the other discipline. The courses finished with a major work which was completed by each student with a discipline-specific scheme framed by a collaborative concept. It was important that the outputs did not blur the interdisciplinary outcomes with individual work, so we could compare the benefits of working solo with working in teams.

In each studio, the teachers structured a sequence of design briefs and tasks which were augmented by the student journal feedback. The tasks aimed to draw out the source of creative design thinking at the conceptual stage, and test the role of trust, immersion, critique, and language. They included: attendance at meetings where students got to know each other (in one of the studios this entailed a three day site visit); presentation of ideas in a 'market place' where students could graphically show their initial design responses and then choose compatible peer partner from another discipline; collaborative development of a 'founding diagram' to provide goal and boundary consensus for both individual designers; 'trading places' where each student critiqued his or her partner's concepts; a 'design-speak' exercise to dissolve disciplinary jargon and develop a common verbal language; 'learning critiquing' through listening and empathizing practices; 'co-owning' the weekly reporting of decision making; and joint presentations of a common idea and its expression in 'discipline specificity' designs.

Data collection methods that informed this research and its thematization are listed in Table 1.

Table 1. Data collection methods.

\begin{tabular}{ll}
\hline Data Collection Method & Details \\
\hline $\begin{array}{l}\text { Weekly teacher/researcher journal } \\
\text { reflections. }\end{array}$ & $\begin{array}{l}\text { Students documented weekly feedback } \\
\text { which formed the brief for weekly tasks. }\end{array}$ \\
\hline $\begin{array}{l}\text { Questionnaire at the beginning and end } \\
\text { of each course. }\end{array}$ & $\begin{array}{l}\text { Quantitative questions were primarily } \\
\text { intended to measure change in attitude } \\
\text { towards interdisciplinary collaborations, } \\
\text { and change in creative design skills as a } \\
\text { result of the interdisciplinary } \\
\text { collaboration. Nineteen questions were } \\
\text { asked requiring numerical responses } \\
\text { based on agreement or disagreement. } \\
\text { Scores for each class were calculated and } \\
\text { averaged. }\end{array}$ \\
& Oualitative
\end{tabular}

Questionnaire at the beginning and end Qualitative questions were intended to of each course.

solicit issues, techniques and successes. The questions were designed to assess how the collaborations helped their design work, and the teaching format/facilitation techniques that worked.

Focus group interview at the end of each course.

\section{Analysis}

The journal provided a basis for cross-checking themes with student design progress.

Questions which had the biggest and most moderate change provided themes for cross-checking written and verbal results. The results were important in verifying the development of creative design skills.

Results were important because they confirmed thematisation, such as design skills, communication, workload and conflict resolution.
Seven (year 3) and ten (year 4) students elaborated on various aspects of the collaborations and their outcomes, discussed what made them better designers, why they preferred interdisciplinary collaboration at the early stages of a project, and where it could be improved.
Transcripts were categorised into thematic headings established in the qualitative questionnaire. Thematic headings were expanded because the results were particularly revealing in identifying design skill development. 


\section{Results}

The results are discussed under broad themes based on the surveys and the focus groups. Some of the themes relate specifically to the development of student skills in the design process which I call 'divergent perspectives', 'reflection and critique' and 'pedagogical maturity'; some became tools for working-'language', 'immersion', 'fairness' and 'trust'. Many of these matters are interrelated, but they were categorised simply as a way of presenting the results in an ordered manner. Quotes noted below were confidential, and are herein attributed to architects (A), landscape architects (LA) and interior architects (IA).

\subsection{Divergent Perspectives}

Arguably the most relevant skill development over the duration of the courses occurred when working with a peer from another discipline. The beginning and ending questionnaires posed identical statements associated with working alone as opposed to working with others. The statement 'collaborating with another discipline makes me understand my own discipline better' showed stronger agreement at the end; while 'designing on my own is better than designing with others', and 'my individuality is stifled by interdisciplinary collaboration' showed stronger disagreement. In the focus groups, many confirmed with overwhelming enthusiasm that interdisciplinary collaboration positively influenced their own work. For example, it 'generates ideas I would never have considered' (A), 'the best projects were the ones that worked together, even though they were mostly individual assignments'(LA) and it 'challenged ideas and made an enormous improvement' (LA). An ah-ha moment of the third-year cohort came when 'our projects were ten times better than our first (non-collaborative) hand in' (LA). The interdisciplinary collaboration was 'light breaking' (A). On this basis, I argue that the students achieved better understanding of the design, and they obtained this primarily by collaborating with someone, who in these courses, was from another discipline.

All students recognized a key value of interdisciplinary collaboration: a common phrase used in the commentary and the focus groups was that they obtained 'a different angle' (IA, LA) on their problem than they would have had either from self-critique or from critique from their own disciplinary cohorts. This difference, also phrased as 'new perspective' (LA), 'new value' (IA) and 'looking through other's eyes' (LA), demonstrated the potential for concepts to 'migrate between disciplines' [6]. Students were able to pinpoint these new angles: landscape students in the collaboration with interior architects offered thinking in 'systems diagramming' (IA), interior students had a focus on 'the physical experience'(IA), and landscape students recognised that architects were good at 'form-making, while landscape architects knew context' (LA). By the end of the term, landscape students developed skills in form-making, and architectural students learned to use context as a design generator. These outcomes did not weaken their core disciplinary skills. Instead, rather, they all learned that shortcomings in their own design could be re-addressed through interdisciplinarity. How did this change in attitude and learning occur? One landscape student suggested that when he was stuck, an architect partner opened new options by 're-framing the problem of light in an external space' (LA). This suggests that interdisciplinarity helped them to be divergent.

\subsection{Reflection and Critique}

Critiquing is a valuable skill in designing as it helps one evaluate how a problem is solved and where to go next. Both cohorts agreed. One student stated 'if my partner says 'looks sweet as', that is actually useless, actually useless' (LA). They could not just say that something designed 'looked cool'(LA), they had to say why it was good or bad, they had to help, because they had an investment in making their partner's work good because it would help their own schemes to look cohesive, and would provide principles for their own designs. According to one interior architecture student, the trimester was not so much about drawing, but about 'argument. I now understand what this does to design potential. Dialogue and argument are great tools to express ideas critically. Clear ideas are the tools 
for collaboration.'(IA). Another stated: 'dialogue was a place to find common ground. The drawings were hard to read and too vague, but when we got together and talked we critted [sic] each other's ideas. Then we knew we were on to it'(A). 'Working with someone gives a critical analysis'(LA) of the design ideas. This reaffirmed not only the role of critique, but also the role of language in the studio.

One of the key moments for both classes occurred 'after doing some individual work, we came to the table with an idea' (LA) to discuss and critique. The diagram 'was something to start from.'(IA). The students had used the weekly tasks to develop skills of critique by refining their diagrams so that their concepts clearly guided their project's direction. For both classes, the development of the diagram through discussion became the basis for their design schemes, and the basis for the successful partnerships. It provided a goal for their common work and a boundary for their individual projects. Many presented the diagram in the final presentation as the seed of their design concept, demonstrating that they had learnt that design is a critical process.

Another important moment entailed the dissolution of fears. There was trepidation at the beginning of both courses that collaboration entailed compromise: that someone had to back down in the decision-making process. The concern was underpinned by the argument that 'everyone is different' (IA), and 'tasks will be done differently by different disciplines'(IA). Early face-to-face feedback identified this problem, and teachers were able to show ways of critiquing others' ideas safely and move productively and creatively to consensus decision making, rather than fear compromise. Learning to critique brought 'more confidence in their skills.' (IA). And there was strong agreement in the questionnaire that they understood their own discipline better at the end of the course. That students needed to be critical to make that statement.

\subsection{Pedagogical Maturity}

In the focus groups, there was further evidence about the importance of pedagogic maturity. Fourth-year students clearly portrayed a better appreciation of critiquing than third-year students. This reaffirms the commentary from Wood [23] that interdisciplinarity helps when students are pedagogically advanced. The fourth-year students talked a lot about the value of the 'other' perspective, and how this knowledge helped them to use the other's skills for design. On the other hand, third-year students spent a lot of time in the focus group discussing the presentation skills of the other discipline: i.e., which cad platform they used, how their graphics were interpreted. They were concerned that there was too much work and that the tutors did not agree on everything, though the 4th years did say this as well, but to a lesser extent. Generally, it revealed that the fourth-year students were just a bit better equipped pedagogically to draw benefit from the interdisciplinary collaboration. This demonstrates the value of knowing your own discipline. Maybe, also, they were closer to going into the workforce and knew that interdisciplinary collaboration would soon be a fact of life.

\subsection{Language}

Communication - listening and empathizing - was identified as a key ingredient in addressing issues, and one of the early problems was understanding disciplinary jargon. Students had to rephrase and explain what seemed intuitive. The interdisciplinarity made them work harder to convey design ideas to their audience, but the outcome was enlightening. They had to learn 'their place in the world better' (IA).

This presented obstacles, but both groups of students soon realized after embarking on early discussions around a diagram, that the other discipline's jargon was 'another way of looking at things'(IA). They became absorbed and immersed in the language of the other discipline. In this sense, students soon realized that a new language offered a new meaning to experiences and phenomena that they previously either had not considered or were unexcited about. Design language is often imbued with metaphors that somehow represent accidental ideas or similarities outside their real meanings. Immersion in the 
language of the disciplines and its re-expression is a key aspect of the creative force of design. Students were encouraged to learn this quickly in these studios to their advantage.

\subsection{Immersion}

The feedback revealed that students in both courses learnt that their interdisciplinary peers, if good at critique, could be a better source of inspiration than tutors, because they are available all the time. 'Design moves fast' (A) so it needed greater attendance, more meetings than were formally scheduled where skills in critique were invaluable. Through these meetings, students became immersed in the abstract space that they shared, which helped their own individual designs. They learnt they had to be committed and trustworthy: 'one couldn't take a couple of days off because it would mean that the partner would progress ahead, and then have to wait for the other to catch up.' This is not a problem in disciplinary collaboration, but is in interdisciplinary collaboration.

\subsection{Fairness}

Interdisciplinary collaborations have the potential to be plagued by both the reality and the perception of unfairness. Students stressed the importance that the collaboration had to be fair and equal. They wanted tasks where there was an equal amount of work for each discipline to do, so it never felt such as one discipline was doing more than the other. They also had to work around different timetables and different submission dates in other classes which hampered progress in the collaboration, and thereby affect the partner. In one class, there was an uneven ratio which imbalanced a few of the collaborations. This was unfair. Teachers need to plan these classes carefully around other timetables and workloads. And they need to be clear about the impact of collaborations on the marking process because, as some third-year students noted collaboration is very time-consuming: it is 'twice as much work'(LA).

\subsection{Trust}

Another concern was the compatibility of the partner. Students were very happy with two-person partnerships. Bigger groups are 'unwieldy, hard to manage' (LA). The process of selecting partners was subject of much discussion in the focus groups. The problematic partnerships were ones where it was obvious that there was no cohesiveness in the final design. They generally occurred when one of the partners did not turn up or was not as committed as the other. The individuals with lazy partners were adamant that the design process which entailed collaboration was not successful, and either did not want to conduct it again or wanted to be very careful about choosing a partner.

Trust also has a positive spin. If one trusts one's partner and is respectful of their ideas, it 'makes you work twice as hard, because you don't want to let them down'(LA).

\section{Discussion}

\subsection{The Pedagogical Basis for Interdisciplinary Collaboration in the Design Process}

Design as a creative process does not follow any linear formula; it is a system that needs, in no particular order or emphasis, a grounding in knowledge, ideation, some introspection, some confidence, some experimentation, iteration and testing. It is a process that repeats itself in the life of a design as it develops. This research has shown that interdisciplinary collaborators have the potential, above all else, to encourage their partners to look more widely at the problem and its context, and to develop critical judgement and skills in deframing and reframing concepts, which is a key part of this process of experimentation and iteration. These skills in critical judgement are borne out of divergent perspectives-a shifted view that allows one to look at an idea put forward and test it in a new light. Ideation may be best as an individual pursuit, but interdisciplinary collaboration encourages students to immerse themselves in design once they have brought 'something to the table' to be sufficiently confident in their own knowledge and still inquisitive enough to want to explore creativity and the possibilities in the unknown. 


\subsection{Effective Teaching/Facilitation Techniques}

Based on the thematised results of the research, there may be two key interrelated approaches to teaching that can be used to help students develop techniques for learning in these studios. The first magnifies the essence of interdisciplinarity, charting a course into the unknown world of creativity through immersive operations and new communication skills. The second is a safety check, a balance to the immersive potential, reaffirming work practice principles that enable students to feel comfortable that experimentation will not lead to their own failure.

Immersion.

Interdisciplinarity accelerates the process of learning the skills of being critical. The speed of the course, the cooperation of partners and the new languages they learn can only be meaningfully used if there is a large degree of immersion in the abstract space of the design. This immersion can happen in a number of ways and the teaching programme should be set up to enable this:

- Ensuring that, early on, there is a founding idea or frame expressed as a diagram that guides the progressive development of the project;

- Encouraging different interpreations of the context by different students to provide different ways of seeing the problematic; and

- $\quad$ Ensuring that there are regular exercises that will require interaction between students to keep up, push the envelope and continue the process of design iteration and experimentation in between class.

New language techniques.

Discussion is a fundamental part of learning to design with interdisciplinary collaborators. Teaching techniques need to

- Encourage deconstruction of inaccessible jargon so that the student has clarity in ideation and the interdisciplinary peer can understand and work with shared ideas;

- Conversely make use of disciplinary jargon as a generative source of different ways of seeing new possibilities; and

- Providing advice on how to be critical. Critiquing is a basic skill in communicating and listening without which the studio would flounder. Students need to be taught how to critique early in the course.

Trust.

While there is a platform for creativity offered by immersion and new language techniques, teachers need to be wary that students are entering into something that is perhaps unknown, with other students that they probably have not worked with before. So, a gentle caveat to teachers is to affirm that basic work practices provide a sense of safety in experimentation in this interdisciplinary studio. This should entail

- ensuring workloads and partnerships are equal;

- that students are encouraged to have and to give equal voice in their partnerships and that partnerships encourage an empathetic sense of working for each other;

- $\quad$ providing a basis for partners to get to know and trust each other (e.g., site excursions);

- Ensuring that students have knowledge-based pedagogical maturity of the principles and background of their disciplines. Students cannot come to the table unless they are confident of their own knowledge. If students are at earlier stages in the programme, they would need to be provided a platform to undertake this interdisciplinarity.

\section{Conclusions}

Conclusions from this research relate to two key areas. There is evidence that there is a pedagogical basis that interdisciplinary practices help students to learn techniques of divergent thinking and critique in the design process; and linked to this, there are some important teaching techniques that appear to be effective in structuring interdisciplinary design studios. They include specifically a number of permutations for immersing the 
students in the project; adopting and adapting language so that it communicates clearly and acts generatively; and providing safety for experimentation.

The benefit of this research can be seen to illuminate Stan Allen's pedagogical tasks, mentioned earlier [3], and advance the potential of the future spatial design school. The first task of the future school is to recognise that spatial design students entering an interdisciplinary studio will have the wherewithal to find alternative practices to address wicked problems in a world where the scope for spatial designers is increasingly changing. The second is that by working with interdisciplinary partner students, they will have spent more time finding context, interpreting problems, and using generative language to create divergent possibilities instead of launching into quick and one-dimensional solutions. The third is that being better equipped with critical judgement, and clarifying language and diagramming skills, that the students will be able to work in future projects more productively and effectively.

With these qualities the student may become not just a good spatial designer to benefit a project team, and not just deeply proficient in arguing with clarity for and against a design, but also a touchstone who can scratch away the surface of interdisciplinary collaborators in complex projects that will become more commonplace in today's climate threatened and socially pluralistic cities and landscapes.

Funding: This research received no external funding. It was conducted while the author was employed for teaching at Victoria University Wellington and University of Technology Sydney.

Institutional Review Board Statement: The study was conducted according the approval of the Ethics Committee of Victoria University of Wellington.

Informed Consent Statement: Informed consent was obtained from all subjects involved in the study.

Data Availability Statement: The author holds all data reported in this paper.

Conflicts of Interest: The author declares no conflict of interest.

\section{References}

1. Garber, M. Shakespeare after All; Knopf Doubleday: New York, NY, USA, 2005; p. 450.

2. Shakespeare, W. As You Like It; Act 1 Scene ii; First Avenue Editions: New York, NY, USA, 2015.

3. Thorne, M. Real Space, Virtual Space What Really matters? In Space Matters. Exploring Spatial Theory and Practice Today; Feiress, L., Ed.; Ambra: Vienna, Austria, 2013; pp. 26-44.

4. Jones, C. Designing Designing; Longman: London, UK, 1991.

5. Bowring, J. Increasing the critical mass: Emphasising critique in studio teaching. Landsc. Rev. 2000, 6, 41-52.

6. Moore, K. Overlooking the Visual: Demystfying the Art of Design; Routledge: Abingdon, UK, 2010.

7. Dorst, K.; Kaldor, L.; Klippan, L.; Watson, R. Designing for the Common Good; Bis Publishers: Amsterdam, The Netherlands, 2016.

8. Dorst, K. Frame Creation and Design in the Expanded Field. She-Ji Econ. Innov. 2015, 1, 22-33. [CrossRef]

9. Van Schaik, L. Spatial Intelligence: New Futures for Architecture; Wiley: Chichester, UK, 2008.

10. Prochazka, E. Flagship Europe: Space and Design Strategies on Tour. In Space Matters. Exploring Spatial Theory and Practice Today; Feiress, L., Ed.; Ambra: Vienna, Austria, 2013; p. 11.

11. Zinsmeister, A. The Art of Thinking and Designing Space. In Space Matters. Exploring Spatial Theory and Practice Today; Feiress, L., Ed.; Ambra: Vienna, Austria, 2013; p. 36.

12. Krauss, R. Sculpture in the Expanded Field. October 1979, 8, 31-44. [CrossRef]

13. Rendell, J. Art and Architecture, A Place Between; IB Taurus: London, UK, 2006.

14. Burry, M.C. Towards Meeting the Challenges of Facilitating Transdisciplinarity in Design Education, Research and Practice. In Design Innovation for the Built Environment-Research by Design and the Renovation of Practice; Hensel, M., Ed.; Routledge: London, UK, February/March; 2012; pp. 53-66.

15. Bryant, M. Touchstones in Design. In Perspectives on Architectural Design Research; Moloney, J., Smitheram, J., Twose, S., Eds.; AADR: Baunach, Germany, 2015.

16. Westley, F.; McGowan, K. Design Thinking, wicked problems, Messy Plans. In Projective Ecologies; Reed, C., Lister, N., Eds.; Harvard University Graduate School of Design, Actar Publishers: Cambridge, MA, USA, 2014; pp. 290-311.

17. Gallopin, P.; Raskin, P. Global Sustainability: Bending the Curve; Routledge: Florence, Italy, 2002.

18. Polk, M. Transdiscplinary co-production: Designing and testing a transdisciplinary research framework for social problem solving. Futures 2014, 65, 110-122. [CrossRef]

19. Healey, P. Planning through debate: The communicative turn in planning theory. Town Plan. Rev. 1992, 63, 143-152. [CrossRef] 
20. Scholz, R.; Steiner, G. The real type and ideal type of transdisciplinary processes: Part I-Theoretical Foundations. Sustain. Sci. 2015, 10, 527-544. [CrossRef]

21. Krippendorf, K. Redesigning design. In Design-Pleasure or Responsibility?; Tahkokallio, P., Vihma, S., Eds.; University of Art and Design: Helsinki, Finland, 1995; pp. 138-162.

22. Wood, G. Interdisciplinary Working in Built Environment Education. Educ. Train. 1999, 41, 373-380. [CrossRef]

23. Feast, L. Epistemological Positions Informing Theories of design Research: Implications for Design Discipline and Design Practice [Online] 2010. Available online: www.drs2010.umontreal.ca/data/pdf/040.pdf (accessed on 12 September 2014).

24. Duhigg, C. What Google Learned from Its Quest to Build the Perfect Team. New York Times, 2016. Available online: https: //www.nytimes.com/2016/02/28/magazine/what-google-learned-from-its-quest-to-build-the-perfect-team.html (accessed on 13 June 2016).

25. Evans, R. In front of Lines that Leave Nothing Behind. In Architectural Theory since 1968; Hays, K.M., Ed.; MIT Press: Cambridge, MA, USA, 2000; pp. 482-489.

26. Botterill, M. Behind the Screen: Intergroup Collaboration in Developing University-based Online Learning Resources. Ph.D. Thesis, RMIT University, Melbourne, Australia, 2013.

27. Reiser, J.; Umemoto, N. Atlas of Novel Tectonics; Princeton: New York, NY, USA, 2006; p. 126.

28. Wheatley, M.J. Leadership and the New Science: Learning about Organization from an Orderly Universe; Berrett-Koehler Pub: Oakland, CA, USA, 1994.

29. Cowdroy, R.; de Graff, E. Assessing highly creative ability. Assess. Eval. High. Educ. 2005, 30, 507-518. [CrossRef]

30. Press, J. Soul- Searching: Reflections from the Ivory Tower. J. Archit. Educ. 1998, 51, 233-242. [CrossRef]

31. Cowdroy, R.; Williams, A. Assessing creativity in the creative arts. Art Des. Commun. High. Educ. 2006, 5, 97-117. [CrossRef]

32. Downton, P. Design Research; RMIT: Melbourne, Australia, 2005.

33. Wagner, M.; Gansemer-Topf, A. Learning by teaching others: A qualitative study exploring the benefits of peer teaching. Landsc. J. 2005, 24, 198-208. [CrossRef]

34. Millis, B.; Cottell, P. Cooperative Learning for Higher Education Faculty; Oryx: Phoenix, Maricopa, 1997.

35. Chickering, A.; Ehrmann, S. Implementing the Seven principles: Technology as lever. AAHE Bull. 1996, 49, 3-6.

36. Matthews, K.E.; Dwyer, A.; Hine, L.; Turner, J. Conceptions of students as partners. High. Educ. 2018, 76, 957-971. [CrossRef]

37. Murphy, E. Recognising and promoting collaboration in an online asynchronous discussion. Br. J. Educ. Technol. 2004, 35, 421-431. [CrossRef]

38. Sanoff, H. Community Based Design Learning: Democracy and Collective Decision Making. In Design Studio Pedagogy: Horizons for the Future; Salama, A., Wilkinson, N., Eds.; Urban International Press: Gateshead, UK, 2007; pp. 21-40.

39. Baumber, A.; Kligyte, G.; van der Bijl-Brouwer, M.; Pratt, S. Learning together: A transdisciplinary approach to student-staff partnerships in higher education. High. Educ. Res. Dev. 2020, 39, 395-410. [CrossRef]

40. Kendall, S. Teaching studio exercises to help students manage distributed design. In Design Studio Pedagogy: Horizons for the Future; Salama, A., Wilkinson, N., Eds.; Urban International Press: Gateshead, UK, 2007; pp. 167-186.

41. Deming, M.; Swaffield, S. Landscape Architecture Research; Wiley: Hoboken, NJ, USA, 2011. 